\title{
THE REPRESENTATIVE CONSUMER IN THE NEOCLASSICAL GROWTH MODEL WITH IDIOSYNCRATIC SHOCKS*
}

\section{Lilia Maliar and Serguei Maliar**}

WP-AD 2002-20

Correspondence: Universidad de Alicante, Departamento de Fundamentos del Análisis Económico, Campus San Vicente del Raspeig, Ap. Correos 99, 03080 Alicante, Spain. E-mails: maliarl@merlin.fae.ua.es and maliars@merlin.fae.ua.es.

Editor: Instituto Valenciano de Investigaciones Económicas, S.A.

Primera Edición Octubre 2002

Depósito Legal: V-4035-2002

IVIE working papers offer in advance the results of economic research under way in order to encourage a discussion process before sending them to scientific journals for their final publication.

\footnotetext{
* We wish to express our special gratitude to associate editor Per Krusell for many valuable suggestions. We have also benefited from the comments of two anonymous referees, Jordi Caballe, Finn Kydland, Albert Marcet, Franck Portier, Michael Reiter and Andrew Scott. We are grateful to Morten Ravn for his guidance. All errors are ours. This research was partially supported by the Instituto Valenciano de Investigaciones Económicas and the Ministerio de Ciencia y Tecnología, BEC 2001-0535.

** Maliar and S. Maliar: Universidad de Alicante.
} 


\title{
THE REPRESENTATIVE CONSUMER IN THE NEOCLASSICAL GROWTH MODEL WITH IDIOSYNCRATIC SHOCKS
}

\author{
Lilia Maliar and Serguei Maliar
}

\begin{abstract}
A B S T R A C T
This paper studies a complete-market version of the neoclassical growth model, where agents face idiosyncratic shocks to earnings. We show that if agents possess identical preferences of either the CRRA or the addilog type, then the heterogeneous-agent economy behaves as if there was a representative consumer who faces three kinds of shocks, to preferences, to technology and to labor. We calibrate and simulate the constructed representative-consumer models. We find that idiosyncratic uncertainty can have a non-negligible effect on aggregate labor-market fluctuations.
\end{abstract}

JEL Classification: C73, D90, E21

Keywords: neoclassical growth model, heterogeneous agents, aggregation, business cycles, idiosyncratic shocks. 


\section{Introduction}

Many recent papers have studied the implications of heterogeneous-agent models where agents experience idiosyncratic shocks to their earnings, e.g., Huggett (1993), Aiyagari (1994), Kydland (1995), Castañeda, Díaz-Giménez and Ríos-Rull (1998), Krusell and Smith (1998). The analysis of equilibrium in models with idiosyncratic uncertainty relies on numerical methods and can be fairly complicated, especially if idiosyncratic shocks are correlated across agents and thus, have a non-trivial effect on aggregate dynamics. This paper presents a complete-market aggregation result, which under the standard restrictions on preferences, can simplify the equilibrium characterization: we can restore the equilibrium in a heterogeneous-agent economy essentially by solving a one-consumer model. In particular, we can easily study the effect of the idiosyncratic productivity shocks on the aggregate dynamics.

Our analysis is carried out in the context of a heterogeneous-agent variant of the standard neoclassical growth model by Kydland and Prescott (1982). Our aggregation result is as follows: If agents possess identical preferences of either the CRRA or the addilog type, then the heterogeneous-agent economy behaves as if there was a representative consumer who faces three kinds of shocks, to preferences, to technology and to labor. Specific assumptions about wealth distribution and the process for idiosyncratic shocks do not affect the structure of the constructed representative-consumer model but merely the stochastic properties of shocks in such a model. We shall emphasize that "shocks from aggregation" appear as a consequence of the assumption of idiosyncratic uncertainty and are not present in the representativeconsumer models, constructed under the assumption of time-invariant individual characteristics, as in, e.g., Chatterjee (1994), Atkeson and Ogaki (1996), Caselli and Ventura (2000), Maliar and Maliar (2000, 2001).

A starting point for our analysis is the result of aggregation in the equilibrium point by Constantinides (1982), who shows that if a representative consumer is to replicate the aggregate behavior of a heterogeneous-agent economy for just one fixed wealth distribution and for just one fixed (equilibrium) price vector, then the representative consumer exists with virtually no restrictions on the individual preferences. This result is shown in two steps: First, the heterogeneous consumers are replaced by a social planner who maximizes the weighted sum of the individual utility functions, and secondly, the planner is replaced by a "composite" consumer who maximizes a "social utility function" of aggregate quantities. With the welfare weights 
in the inverse proportion to the equilibrium marginal utilities of consumption, the constructed one-consumer model yields the aggregate equilibrium allocation in the decentralized economy.

Under the construction of Constantinides (1982), the social utility function is defined implicitly, as a maximum point of the weighted sum of the individual utility functions. In terms of our model, this definition implies that the social utility function depends on the aggregate quantities, the distribution of welfare weights and the distribution of labor productivities. In general, there is no easy way of characterizing the relationship between the distributions and the shape of the social utility function. To know what the social utility function looks like, we need, essentially, to solve for the equilibrium in the heterogeneous-agent economy. In some cases, however, it is possible to construct the social utility function analytically. Our examples of aggregation are precisely two such cases. The property, which is common to both our examples, is that the functional form of the social utility function is invariant to changes in the distributions of welfare weights and productivities; the distributions affect only the parameters of the social utility function. Our results lie somewhere between Gorman's (1953) exact aggregation, when social preferences are the same for all distributions of individual characteristics, and Constantinides's (1982) aggregation in the equilibrium point, when the social preferences depend on the distribution of individual characteristics in a manner, which is difficult to characterize.

With the aggregation result in hand, we can easily investigate quantitative predictions of models with, literally, millions of agents. We therefore complement the theoretical analysis by studying the implications of a calibrated version of our model. We assume that the process for idiosyncratic shocks is given by the sum of the individual and aggregate components. We calibrate the individual characteristics by using data from the Panel Study of Income Dynamics (PSID). The aggregate component is chosen so that the process for technology shocks, in our heterogeneous-agent model, is identical to the one used in the literature for parametrizing the benchmark homogeneous-agent setup. The remaining parameters are fixed so that the model reproduces selected time series observations on the U.S. economy. We find that in both the CRRA and addilog cases, the impact of the preference shocks on the aggregate dynamics is quantitatively small. The effect associated with the labor shocks is, however, sizeable. Such shocks can significantly increase the volatility of working hours and can lead to acyclical or even countercyclical behavior of labor productivity. 
The paper is organized as follows: Section 2 formulates a heterogeneousagent model. Section 3 derives aggregation results under the assumptions of the CRRA and addilog types of preferences. Section 4 describes the methodology of the numerical analysis and discusses the simulation results, and finally, Section 5 concludes.

\section{The economy}

Time is discrete and the horizon is infinite, $T=0,1, \ldots, \infty$. The environment is composed of a set of heterogeneous agents $S=[0,1]$. Heterogeneity is in the dimensions of initial endowment and skills. The measure of agent $s$ in the set $S$ is $d \omega^{s}$, and the total measure is normalized to one, $\int_{S} d \omega^{s}=1$. Agents receive random shocks to skills. We use $\beta_{t}^{s}$ to denote the level of skills of agent $s$ in period $t$. The distribution of skills among agents, which we denote $B_{t} \equiv$ $\left\{\beta_{t}^{s}\right\}^{s \in S}$, follows a first-order Markov process with transitional probability $\Pi\left\{B_{t+1}=B^{\prime} \mid B_{t}=B\right\}_{B^{\prime}, B \in \Re}$, where $\Re \subset R_{+}^{S}$. Idiosyncratic shocks to skills of different agents can be correlated. The economy starts out with $B_{0} \in \Re$.

In each period $t$, an infinitely-lived agent $s \in S$ chooses consumption, $c_{t}^{s}$, and leisure, $l_{t}^{s}$, to maximize the expected discounted sum of the period utility functions. The discount factor is $\delta \in(0,1)$. The period utility function, $u\left(c_{t}^{s}, l_{t}^{s}\right)$, is continuously differentiable, strictly increasing in both arguments, and strictly concave. The agent is endowed with one unit of time which can be split between work, $n_{t}^{s}$, and leisure, $l_{t}^{s}=1-n_{t}^{s}$. The common wage per unit of efficiency labor is $w_{t}$. The agent also gets income from renting capital, $k_{t}^{s}$. The interest rate is $r_{t}$. The depreciation rate of capital is $d \in(0,1]$. The economy has a complete set of markets, i.e., the agents can trade state-contingent claims. The agent's $s$ portfolio of claims is denoted by $\left\{m_{t}^{s}(B)\right\}_{B \in \Re}$. The claim of type $B \in \Re$ pays one unit of $t+1$ consumption good in the state $B$ and nothing otherwise. The price of such a claim is $p_{t}(B)$.

Therefore, the problem solved by agent $s$ is

$$
\max _{\left\{c_{t}^{s}, n_{t}^{s}, k_{t+1}^{s}, m_{t+1}^{s}(B)\right\}_{B \in \Re, t \in T}} E_{0} \sum_{t=0}^{\infty} \delta^{t} u\left(c_{t}^{s}, 1-n_{t}^{s}, g^{t}\right)
$$


subject to

$$
c_{t}^{s}+k_{t+1}^{s}+\int_{\Re} p_{t}(B) m_{t+1}^{s}(B) d B=\left(1-d+r_{t}\right) k_{t}^{s}+w_{t} g^{t} n_{t}^{s} \beta_{t}^{s}+m_{t}^{s}\left(B_{t}\right),
$$

where $g$ is the rate of the labor-augmenting technology progress, which is introduced to allow for the steady state growth of the economy. The operator $E_{t}$ denotes the expectation, conditional on the information available in period $t$. Initial holdings of capital and contingent claims, $k_{0}^{s}$ and $m_{0}^{s}$, are given.

The output $y_{t}$ is produced according to a two-input production function, $y_{t}=f\left(k_{t}, N_{t}\right)$, where $k_{t}$ and $N_{t}$ are the amounts of capital and efficiency labor, respectively. We adopt the common and convenient Cobb-Douglas specification of production $f\left(k_{t}, N_{t}\right)=k_{t}^{\alpha} N_{t}^{1-\alpha}$, with $\alpha \in(0,1)$. Given such a constant-returns-to-scale parametrization of the production function, the factor prices $r_{t}$ and $w_{t}$, relevant for the consumers' decisions, satisfy the aggregate marginal product conditions: $r_{t}=\partial f / \partial k_{t}$ and $w_{t}=\partial f / \partial N_{t}$. Capital and labor inputs are given by the sum of capital holdings and efficiency labor of all the agents, $k_{t}=\int_{S} k_{t}^{s} d \omega^{s}$ and $N_{t}=g^{t} \int_{S} n_{t}^{s} \beta_{t}^{s} d \omega^{s}$.

It is convenient to introduce a new variable "normalized individual skills", defined as $b_{t}^{s} \equiv \beta_{t}^{s} / \beta_{t}$, where $\beta_{t} \equiv \int_{S} \beta_{t}^{s} d \omega^{s}$ represents the aggregate (average) level of skills in the economy. Furthermore, let us define two aggregate labor market variables,

$$
n_{t} \equiv \int_{S} n_{t}^{s} d \omega^{s} \quad \text { and } \quad h_{t} \equiv \int_{S} n_{t}^{s} b_{t}^{s} d \omega^{s}
$$

We will refer to $n_{t}$ and $h_{t}$ as the aggregate physical and aggregate efficiency working hours, respectively. The variables $N_{t}$ and $h_{t}$ are related as $N_{t}=$ $g^{t} h_{t} \beta_{t}$. The relation between $n_{t}$ and $h_{t}$ will be discussed later on.

In terms of $h_{t}$, the production function can be written as $f\left(k_{t}, h_{t}\right)=$ $\theta_{t} k_{t}^{\alpha}\left(g^{t} h_{t}\right)^{1-\alpha}$, where $\theta_{t} \equiv \beta_{t}^{1-\alpha}$. The economy's Resource Constraint $(R C)$ is therefore given by

$$
c_{t}+k_{t+1}=(1-d) k_{t}+\theta_{t} k_{t}^{\alpha}\left(g^{t} h_{t}\right)^{1-\alpha},
$$

where $c_{t}=\int_{S} c_{t}^{s} d \omega^{s}$ is the aggregate consumption.

Formally, a competitive equilibrium is defined as a sequence of contingency plans for allocations of the consumers $\left\{c_{t}^{s}, n_{t}^{s}, k_{t+1}^{s}, m_{t+1}^{s}(B)\right\}_{B \in \Re, t \in T}^{s \in S}$, 
for the prices $\left\{p_{t}(B), r_{t}, w_{t}\right\}_{B \in \Re, t \in T}$, for aggregate factor inputs $\left\{k_{t}, h_{t}\right\}_{t \in T}$ such that $(i)$ given the prices, $\left\{c_{t}^{s}, n_{t}^{s}, k_{t+1}^{s}, m_{t+1}^{s}(B)\right\}_{B \in \Re, t \in T}^{s \in S}$ solves the utility maximization problem (1), (2) of each consumer $s ;(i i)\left\{r_{t}, w_{t}\right\}_{t \in T}$ are given by the marginal productivities of aggregate capital and labor; (iii) markets for goods, capital, labor and contingent claims clear. Moreover, the plans are such that $c_{t}^{s} \geq 0$, and $1 \geq n_{t}^{s} \geq 0$ for all $s, t$, and $r_{t}, w_{t}, k_{t}>0$ for all $t$. We restrict our attention to an interior equilibrium. We assume that such an equilibrium exists and that it is unique.

\section{The representative consumer}

In an economy with complete markets and without distortions, a competitive equilibrium is Pareto optimal, which is established by the first fundamental theorem of welfare economics (see, e.g., Mas-Colell, Whinston and Green, 1995, Ch. 16). We can therefore infer the equilibrium from the associated planner's problem. For the purpose of constructing the representative consumer, it is convenient to represent the planner's problem in the form of two subproblems. The first subproblem is to distribute the aggregate consumption and working hours between the heterogeneous agents, which delivers the social period utility function,

$$
\begin{aligned}
& U\left(c_{t}, 1-h_{t}, g^{t},\left\{\lambda^{s}, b_{t}^{s}\right\}^{s \in S}\right) \equiv \\
& \max _{\left\{c_{t}^{s}, n_{t}^{s}\right\}^{s \in S}}\left\{\int_{S} \lambda^{s} u\left(c_{t}^{s}, 1-n_{t}^{s}, g^{t}\right) d \omega^{s} \mid \int_{S} c_{t}^{s} d \omega^{s}=c_{t}, \int_{S} n_{t}^{s} b_{t}^{s} d \omega^{s}=h_{t}\right\},
\end{aligned}
$$

where $\left\{\lambda^{s}\right\}^{s \in S} \subset R_{+}^{S}$ is a given distribution of welfare weights, with the mean normalized to one, for convenience, $\int_{S} \lambda^{s} d \omega^{s}=1$. The second subproblem is to solve for the aggregate allocation that maximizes the social preferences:

$$
\max _{\left\{c_{t}, h_{t}, k_{t+1}\right\}_{t \in T}} E_{0} \sum_{t=0}^{\infty} \delta^{t} U\left(c_{t}, 1-h_{t}, g^{t},\left\{\lambda^{s}, b_{t}^{s}\right\}^{s \in S}\right) \quad \text { s.t. } \quad R C .
$$

The following proposition characterizes the exact relationship between the decentralized and the planner's economies. 
Proposition 1 For any distribution of initial endowments in the decentralized economy (1) - (4), there exists a distribution of welfare weights in the planner's economy (5), (6), such that a competitive equilibrium is a solution to the planner's problem. ${ }^{1}$

\section{Proof. See Appendix A.}

The above construction of the planner's problem has a long history, which dates back to Samuelson (1956), who introduced the notion of a social utility function. Negishi (1961) pointed out that the competitive equilibrium can be found by maximizing the weighted sum of the individual utility functions, subject to the economy's resource constraint. Finally, Constantinides (1982) singled out a subproblem of the planner's problem that defines the social utility function.

As pointed out in Constantinides (1982), the function $U$ can be interpreted as the utility function of one composite consumer. Indeed, the oneconsumer model (6), by construction, rationalizes the equilibrium behavior of aggregate variables observed in the decentralized economy. In general, the shape of the social utility function will "depend on the equilibrium", or, in other words, on the specific distributions of welfare weights and labor productivities. The consequence is that we need, essentially, to solve for the equilibrium first-which involves exploring the interaction between preferences and the associated heterogeneity-to know what the social utility function looks like. Although the division of the planner's problem into two subproblems simplifies the task (it allows us to compute the social utility function by solving a static optimization problem, and not a dynamic one), the numerical computation can be still burdensome.

It is therefore of interest to distinguish the cases in which the social preferences can be constructed analytically. The well-known example in the literature is Gorman's (1953) aggregation, in which the preferences of the economy as a whole do not depend on the wealth distribution (or, equivalently, on the welfare weights distribution). If agents differ only in wealth, the existence of Gorman's (1953) representative consumer requires that the individual preferences are similarly quasi-homothetic (homothetic and identical up to possibly different translated origins). However, if agents are subject to idiosyncratic

\footnotetext{
${ }^{1}$ The correspondence between the distribution of initial endowments and the distribution of welfare weights is defined by the consumers' expected lifetime budget constraints (see Maliar and Maliar, 2001, for a discussion).
} 
productivity shocks, Gorman's (1953) aggregation is not possible even if the individual preferences are similarly quasi-homothetic.

It turns out that in some cases, we can derive the social utility function without having Gorman's (1953) representative consumer. Below, we establish two such cases. Their common property is that the functional form of the social utility function is invariant to changes in the distributions of welfare weights and productivities; even though the distributions are part of the social utility function, they enter in a simple way, affecting only the preference parameters. We refer to our construction as "aggregation" and call the constructed consumer "representative", though this terminology does not have the standard meaning, as employed in the literature on aggregation.

Before presenting the results, we shall illustrate our aggregation technique by way of an example. It turns out that the simplest possible setup, for which our aggregation works, is not the one with productivity shocks but the one with preference shocks.

Example 1 Consider a version of the economy of Section 2, in which there is no long-run growth. The skills of all agents are identical, $\beta_{t}^{s}=\beta_{t}$ for all $s$, and leisure is not valuable, $n_{t}^{s}=1$ for all $s$. Assume that the individual preferences are $E_{0} \sum_{t=0}^{\infty} \delta^{t} \phi_{t}^{s} u\left(c_{t}^{s}\right)$, where $\phi_{t}^{s}$ is an individual-specific shock to preferences that follows a first-order Markov process. In such an economy, the social utility function is defined by

$$
U\left(c_{t},\left\{\lambda^{s}, \phi_{t}^{s}\right\}^{s \in S}\right) \equiv \max _{\left\{c_{t}^{s}\right\}^{s \in S}}\left\{\int_{S} \lambda^{s} \phi_{t}^{s} u\left(c_{t}^{s}\right) d \omega^{s} \mid \int_{S} c_{t}^{s} d \omega^{s}=c_{t}\right\}
$$

Suppose that the individual utility function is of the CRRA type, $u\left(c_{t}^{s}\right)=$ $\frac{\left(c_{t}^{s}\right)^{1-\nu}}{1-\nu}$ with $\nu>0, \nu \neq 1$. The first-order condition of $(7)$ is therefore:

$$
\lambda^{s} \phi_{t}^{s}\left(c_{t}^{s}\right)^{-\nu}=z_{t},
$$

where $z_{t}$ is the Lagrange multiplier associated with the constraint. This condition implies the following formulas for the individual and aggregate consumption:

$$
c_{t}^{s}=z_{t}^{-1 / \nu}\left(\lambda^{s} \phi_{t}^{s}\right)^{1 / \nu} \quad \text { and } \quad c_{t}=z_{t}^{-1 / \nu} \int_{S}\left(\lambda^{s} \phi_{t}^{s}\right)^{1 / \nu} d \omega^{s} .
$$

On eliminating the Lagrange multiplier, we get

$$
c_{t}^{s}=\frac{\left(\lambda^{s} \phi_{t}^{s}\right)^{1 / \nu}}{\int_{S}\left(\lambda^{s} \phi_{t}^{s}\right)^{1 / \nu} d \omega^{s}} c_{t} .
$$


By substituting this result in the definition of the social utility function (7), we obtain

$$
U\left(c_{t},\left\{\lambda^{s}, \phi_{t}^{s}\right\}^{s \in S}\right)=\int_{S} \frac{\lambda^{s} \phi_{t}^{s}}{1-\nu}\left(\frac{\left(\lambda^{s} \phi_{t}^{s}\right)^{1 / \nu}}{\int_{S}\left(\lambda^{s} \phi_{t}^{s}\right)^{1 / \nu} d \omega^{s}} c_{t}\right)^{1-\nu} d \omega^{s}=\frac{\phi_{t} c_{t}^{1-\nu}}{1-\nu}
$$

where $\phi_{t} \equiv\left(\int_{S}\left(\lambda^{s} \phi_{t}^{s}\right)^{1 / \nu} d \omega^{s}\right)^{\nu}$. Hence, we have a closed-form solution for the social utility function, where the variable $\phi_{t}$ can be interpreted as a shock to preferences of the representative consumer.

We now turn back to the economy with idiosyncratic shocks to skills. We present the aggregation results for two cases: one when agents have identical preferences of the CRRA type, and the other when agents have identical preferences of the addilog type. The former preferences are homothetic, while the latter are non-homothetic.

We begin by assuming that the individual utility functions are of the CRRA type:

$$
u\left(c_{t}^{s}, 1-n_{t}^{s}, g^{t}\right)=\frac{\left(\left(c_{t}^{s}\right)^{\mu}\left(\left(1-n_{t}^{s}\right) g^{t}\right)^{1-\mu}\right)^{1-\eta}-1}{1-\eta}, \quad 1>\mu>0, \quad \eta>0 .
$$

The aggregation result here, is as follows:

Proposition 2 Assume (8). Then, the social utility function is

$$
U\left(c_{t}, 1-h_{t}, g^{t},\left\{\lambda^{s}, b_{t}^{s}\right\}^{s \in S}\right)=\Lambda_{t} \frac{\left(c_{t}^{\mu}\left(1-h_{t}\right)^{1-\mu} g^{(1-\mu) t}\right)^{1-\eta}-1}{1-\eta},
$$

where $\Lambda_{t}$ is given by

$$
\Lambda_{t} \equiv\left(\int_{S}\left(\lambda^{s}\right)^{1 / \eta}\left(b_{t}^{s}\right)^{-(1-\mu)(1-\eta) / \eta} d \omega^{s}\right)^{\eta}
$$

Proof. See Appendix A. \|

Since the CRRA utility function (8) is quasi-homothetic, in the economy where agents differ only in wealth, we must have Gorman's (1953) representative consumer. Indeed, if there are no differences in skills, i.e., $b_{t}^{s}=1$ for 
all $t, s$, we have that $\Lambda_{t}$ is constant. Premultiplying the preferences by a constant is a linear transformation of preferences and does not affect the solution. Hence, the aggregate allocation does not depend on a specific wealth distribution. This is precisely what Gorman's (1953) aggregation means. In the presence of idiosyncratic shocks to skills, the variable $\Lambda_{t}$ may change over time. An exception is a limiting, logarithmic case $(\eta=1)$ where we have $\Lambda_{t}=1$ for all $t$.

We next consider the case in which the individual utility functions are of the addilog type:

$$
u\left(c_{t}^{s}, 1-n_{t}^{s}, g^{t}\right)=\frac{\left(c_{t}^{s}\right)^{1-\gamma}-1}{1-\gamma}+A g^{t(1-\gamma)} \frac{\left(1-n_{t}^{s}\right)^{1-\sigma}-1}{1-\sigma}, \quad \gamma, \sigma, A>0 .
$$

The corresponding aggregation result is as follows:

Proposition 3 Assume (11). Then, the social utility function is

$$
U\left(c_{t}, 1-h_{t}, g^{t},\left\{\lambda^{s}, b_{t}^{s}\right\}^{s \in S}\right)=\frac{c_{t}^{1-\gamma}-1}{1-\gamma}+A X_{t} g^{t(1-\gamma)} \frac{\left(1-h_{t}\right)^{1-\sigma}-1}{1-\sigma},
$$

where $X_{t}$ is given by

$$
X_{t} \equiv \frac{\left(\int_{S}\left(\lambda^{s}\right)^{1 / \sigma}\left(b_{t}^{s}\right)^{1-1 / \sigma} d \omega^{s}\right)^{\sigma}}{\left(\int_{S}\left(\lambda^{s}\right)^{1 / \gamma} d \omega^{s}\right)^{\gamma}}
$$

Proof. See Appendix A. \|

Unless $\gamma=\sigma$, the addilog utility function (11) is not similarly quasihomothetic, and aggregation in the sense of Gorman (1953) is not possible, even if the differences in wealth are the only source of heterogeneity. Indeed, even if $b_{t}^{s}=1$ for all $t, s$, we still have that the value of $X_{t} \equiv X$ depends on a specific distribution of welfare weights and affects the marginal rate of substitution between consumption and leisure in the social utility function (12). In the quasi-homothetic case, $\gamma=\sigma$, Gorman's (1953) representative consumer exists if agents are heterogeneous only in wealth (then, $X_{t}=1$ for any distribution of welfare weights), however, it does not exist if agents are 
heterogeneous in both wealth and skills. With idiosyncratic shocks to skills, $X_{t}$ can change over time if $\sigma \neq 1$. The fact that the addilog preferences are consistent with aggregation was first mentioned by Shafer (1977), who showed that such preferences lead to a negative semidefinite Slutsky matrix. Atkeson and Ogaki (1996) derived a closed-form expression for the social utility function for the case in which agents are heterogeneous in wealth.

In order to complete the characterization of the aggregate dynamics, we must also look at the labor-market variables. Note that the "labor" variable in the constructed representative-consumer models is not physical hours worked, $n_{t}$, but rather efficiency hours worked, $h_{t}$. We establish the relationship between $n_{t}$ and $h_{t}$ with the following proposition.

Proposition 4 Assume that all agents have identical preferences of either the CRRA type (8) or the addilog type (11). Then, $n_{t}$ and $h_{t}$ are related as

$$
n_{t}=1-\left(1-h_{t}\right) \cdot \pi_{t}
$$

where in the CRRA case, $\pi_{t}$ is given by

$$
\pi_{t} \equiv \frac{\int_{S}\left(\lambda^{s}\right)^{1 / \eta}\left(b_{t}^{s}\right)^{-(1-\mu+\mu \eta) / \eta} d \omega^{s}}{\int_{S}\left(\lambda^{s}\right)^{1 / \eta}\left(b_{t}^{s}\right)^{-(1-\mu)(1-\eta) / \eta} d \omega^{s}},
$$

and in the addilog case, $\pi_{t}$ is given by

$$
\pi_{t} \equiv \frac{\int_{S}\left(\lambda^{s}\right)^{1 / \sigma}\left(b_{t}^{s}\right)^{-1 / \sigma} d \omega^{s}}{\int_{S}\left(\lambda^{s}\right)^{1 / \sigma}\left(b_{t}^{s}\right)^{1-1 / \sigma} d \omega^{s}} .
$$

Proof. See Appendix A.

The behavior of the aggregate physical hours worked, $n_{t}$, in the studied heterogeneous-agent economies is, therefore, completely characterized by $h_{t}$ and $\pi_{t}$. We refer to the variable $\pi_{t}$ as a labor-input shock.

Summarizing, the fluctuations in the constructed representative-consumer models result from three different kinds of shocks. The first one, $\theta_{t}$, allows for a standard interpretation of technological innovations and is due to the stochastic behavior of the aggregate level of skills, $\theta_{t}=\beta_{t}^{1-\alpha}$. Given that this shock is independent of distributions, its driving process can be modeled as in the benchmark one-consumer setup by Kydland and Prescott (1982). The second kind of shock is given by $\Lambda_{t \square}$ in $\square$ the $\square$ CRRA $\square$ case, $\square$ and $\square$ by $\square X_{t}$ 
in the addilog case. Such shocks cause variations in the preferences of the representative consumer. Specifically, $\Lambda_{t}$ acts as a shock to the discounting of the whole social utility function, whereas $X_{t}$ affects only the discounting of the leisure term. Finally, the third kind of shock, $\pi_{t}$, influences the behavior of physical hours worked, $n_{t}$, exclusively. The stochastic properties of the preference and labor-input shocks depend on specific assumptions about the welfare weights, $\left\{\lambda^{s}\right\}^{s \in S}$, and the normalized skills, $\left\{b_{t}^{s}\right\}^{s \in S}$.

\section{Numerical analysis}

In this section, we complement our theoretical analysis by presenting the results from a numerical exercise. We specifically focus on the question how idiosyncratic productivity shocks can affect aggregate dynamics of the standard neoclassical stochastic growth model. With the aggregation results in hand, we can study this question in a relatively simple manner, since we are able to infer the equilibrium in our heterogeneous-agent economy by essentially solving a one-consumer model. We first outline the methodology of our numerical analysis and then discuss the simulation results.

\subsection{Methodology}

For the most part, our calibration is standard to the real business cycle literature. We set the capital share in the Cobb-Douglas production function at $\alpha=0.36$. The parameters $d$ and $\delta$ and the utility function parameters $\mu$ and $A$ in the CRRA and addilog utility functions, respectively, are chosen so that in the non-stochastic steady state, the homogeneous-agent version of the model replicates the following four statistics: consumption to output ratio $c / y=0.745$, capital to output ratio $k / y=10.237$, per-quarter output growth rate $g=1.0047$, and the average hours worked $n=0.31$. The first three figures are our own estimates, computed from time series data from the U.S. economy (the description of the U.S. data used is provided in Appendix B). The forth figure is the estimate for hours worked, in terms of discretionary time, reported by Juster and Stafford (1991). Regarding the remaining utility function parameters, in the CRRA case, we consider $\eta \in\{0.5,1,2\}$, and in the addilog case, we set $\gamma=1$ and consider $\sigma \in\{0.5,2\}$.

To calibrate idiosyncratic shocks, we assume that the stochastic process for individual skills is additive in the individual and aggregate components, 
$\beta_{t}^{s}=e_{t}^{s}+\beta_{t}$. As regards the individual component, $e_{t}^{s}$, we assume $e_{t}^{s} \sim$ $N\left(0, \nu^{2}\right)$. Under this assumption, the distribution of the normalized skills, $b_{t}^{s}=1+\frac{e_{t}^{s}}{\beta_{t}}$, changes with the aggregate level of skills, $\beta_{t}$, which leads to nontrivial dynamics of the preferences and labor-input shocks over the business cycle. $^{2}$ We examine two values of $\nu \in\{0.2,0.4\}$, which are in line with those used in Aiyagari (1994). Regarding the aggregate level of skills, $\beta_{t}$, we assume that it follows an $A R(1)$ process, $\log \beta_{t}=\rho \log \beta_{t-1}+\varepsilon_{t}$ with $\epsilon_{t} \sim N\left(0, V^{2}\right)$. Given that $\theta_{t}=\beta_{t}^{1-\alpha}$, the corresponding process for the technology shock is $\log \theta_{t}=\rho \log \theta_{t-1}+\varepsilon_{t}(1-\alpha)$. We choose $\rho=0.95$ and $V(1-\alpha)=$ 0.007 , which makes the process for $\theta_{t}$ in our model identical to the one in the standard one-consumer neoclassical stochastic growth model, considered, e.g., in Hansen (1985). Although the individual skills could, in principle, have negative values, this is not very probable under the parameterizations considered here, and has never occurred in our simulations.

Following Kydand $(1984,1995)$, we calibrate the distribution of welfare weights, $\left\{\lambda^{s}\right\}^{s \in S}$, by matching the empirical distribution of hours worked. ${ }^{3}$ We approximate the latter distribution by using the 1989 cross-section from the Panel Study of Income Dynamics (PSID), which provides information about 7114 U.S. households. To be more precise, we first take the variable "annual hours worked by the head of the household" (the PSID mnemonics 16335 ) and normalize its mean to 0.31 . We then set $b_{t}^{s}=1$ for all $s$, and for each considered value of $\eta$ in the CRRA case and $\sigma$ in the addilog case, we solve for the welfare weights satisfying equilibrium conditions (37) and (43), respectively (see Appendix A).

Before computing numerical solutions, we converted the constructed representative-consumer models into stationary ones by using the standard change of variables: $\widetilde{c}_{t}=c_{t} g^{-t}$ and $\widetilde{k}_{t}=k_{t} g^{-t}$. To find numerical solutions, we employ the variant of the parameterized expectation algorithm proposed by den Haan and Marcet (1990). To approximate the conditional expectations, we use the first-order degree exponentiated polynomial. The simulation length is 10000 . The iterations are performed until 5-digit precision in the

\footnotetext{
${ }^{2}$ If we assume that the individual skills are multiplicative in the individual and aggregate components, e.g., $\beta_{t}^{s}=e_{t}^{s} \beta_{t}$ with $\log \left(e_{t}^{s}\right) \sim N\left(0, v^{2}\right)$, then the distribution of the normalized skills, $b_{t}^{s}=e_{t}^{s} / \int_{S} e_{t}^{s} d \omega^{s}$, does not depend on $\beta_{t}$. With a continuum of agents, the preference and labor input shocks therefore exhibit no dynamics.

${ }^{3}$ One can also calibrate the weights to match some other empirical distributions, such as the one of consumption or wealth. The model might have difficulty in accounting for all the distributional facts simultaneously (see Maliar and Maliar, 2001, for a discussion).
} 
polynomial coefficients is enforced.

The simulation results under the CRRA and addilog utility functions are shown in Tables 1 and 2, respectively. For comparison, we also provide the corresponding statistics for the U.S. economy. The statistics $\sigma_{x}$ and $\operatorname{corr}(x, y)$ are the volatility of a variable $x_{t}$ and the correlation between variables $x_{t}$ and $y_{t}$, respectively. The statistics in Tables 1 and 2 are sample averages of the corresponding variables computed for each of 400 simulations. Each simulation has a duration of 157 periods, as do the time series for the U.S. economy. Numbers in brackets are the sample standard deviations of the statistics. Before calculating any statistics, we converted the time series generated by the stationary models into growing ones. To compute the second moments for both the U.S. and the artificial economies, we take the variables that were logged and detrended by using the Hodrick-Prescott filter with a penalty parameter equal to 1600 .

\subsection{Results}

We start by re-examining the quantitative implications of the standard neoclassical stochastic growth model by Kydland and Prescott (1982) (K\&P), where all agents are identical and where only technology shocks occur. In Table 1, we provide the results for such a model under the logarithmic utility function, which is a limiting case of both the CRRA utility function under $\eta=1$ and the addilog utility function under $\gamma=1, \sigma=1$. Kydland and Prescott's (1982) model is known to generate most of the statistics in line with the data but with several notorious exceptions. The most serious failure of the model is its inability to produce the appropriate comovement of labor market variables. Specifically, the model predicts almost perfect positive correlations between working hours and productivity $\left(y_{t} / n_{t}\right)$, between productivity and output, and between working hours and output, whereas in actual economies, such correlations are substantially lower. ${ }^{4}$ The sensitivity results, reported in columns " $K \& P$ " of Tables 1 and 2 , demonstrate that the problems encountered under the benchmark "log-log" parameterization cannot be resolved by changing the parameters of the utility functions.

\footnotetext{
${ }^{4}$ The fact that labor supply and productivity are weakly correlated in the data is known as the "Dunlop-Tarshis observation" after J.Dunlop (1938) and L.Tarshis (1939). The failure of a one-shock neoclassical model to account for the Dunlop-Tarshis observation is well-known in the literature (see Christiano and Eichenbaum, 1992, for a discussion).
} 
Table 1. Selected statistics for the U.S. and artificial economies: the Cobb-Douglas case.

\begin{tabular}{|c|c|c|c|c|c|c|c|c|c|c|}
\hline \multirow{2}{*}{ Statistic } & \multicolumn{3}{|c|}{$\eta=0.5$} & \multicolumn{3}{|c|}{$\eta=1.0$} & \multicolumn{3}{|c|}{$\eta=2.0$} & \multirow{2}{*}{$\begin{array}{c}\text { U.S. } \\
\text { Economy }\end{array}$} \\
\hline & $K \& P$ & $\begin{array}{c}H A \\
v=0.2\end{array}$ & $\begin{array}{c}H A \\
v=0.4\end{array}$ & $K \& P^{b}$ & $\begin{array}{c}H A^{b} \\
v=0.2\end{array}$ & $\begin{array}{c}H A^{b} \\
v=0.4\end{array}$ & $K \& P$ & $\begin{array}{c}H A \\
v=0.2\end{array}$ & $\begin{array}{c}H A \\
v=0.4\end{array}$ & \\
\hline$\sigma_{y}$ & $\begin{array}{c}1.4200 \\
(0.1509)\end{array}$ & $\begin{array}{c}1.4158 \\
(0.1557)\end{array}$ & $\begin{array}{c}1.4220 \\
(0.1594)\end{array}$ & & $\begin{array}{c}1.3243 \\
(0.1341)\end{array}$ & & $\begin{array}{c}1.2426 \\
(0.1406)\end{array}$ & $\begin{array}{c}1.2533 \\
(0.1358)\end{array}$ & $\begin{array}{c}1.2319 \\
(0.1348)\end{array}$ & 1.755 \\
\hline$\sigma_{i} / \sigma_{y}$ & $\begin{array}{c}4.2721 \\
(0.0883)\end{array}$ & $\begin{array}{c}4.2644 \\
(0.0872)\end{array}$ & $\begin{array}{c}4.3483 \\
(0.0956)\end{array}$ & & $\begin{array}{c}3.8903 \\
(0.0732)\end{array}$ & & $\begin{array}{c}3.4925 \\
(0.0587)\end{array}$ & $\begin{array}{c}3.5880 \\
(0.0663)\end{array}$ & $\begin{array}{c}3.5465 \\
(0.0655)\end{array}$ & 2.731 \\
\hline$\sigma_{c} / \sigma_{y}$ & $\begin{array}{c}0.2497 \\
(0.0201)\end{array}$ & $\begin{array}{c}0.2489 \\
(0.0204)\end{array}$ & $\begin{array}{c}0.2550 \\
(0.0197)\end{array}$ & & $\begin{array}{c}0.3083 \\
(0.0130)\end{array}$ & & $\begin{array}{c}0.3884 \\
(0.0077)\end{array}$ & $\begin{array}{c}0.3687 \\
(0.0077)\end{array}$ & $\begin{array}{c}0.3900 \\
(0.0091)\end{array}$ & 0.476 \\
\hline $\operatorname{corr}(i, y)$ & $\begin{array}{c}0.9839 \\
(0.0041)\end{array}$ & $\begin{array}{c}0.9843 \\
(0.0038)\end{array}$ & $\begin{array}{c}0.9815 \\
(0.0040)\end{array}$ & & $\begin{array}{c}0.9880 \\
(0.0028)\end{array}$ & & $\begin{array}{c}0.9918 \\
(0.0020)\end{array}$ & $\begin{array}{c}0.9921 \\
(0.0021)\end{array}$ & $\begin{array}{c}0.9890 \\
(0.0020)\end{array}$ & 0.979 \\
\hline $\operatorname{corr}(c, y)$ & $\begin{array}{c}0.7161 \\
(0.0267)\end{array}$ & $\begin{array}{c}0.7185 \\
(0.0229)\end{array}$ & $\begin{array}{c}0.6391 \\
(0.0257)\end{array}$ & & $\begin{array}{c}0.8953 \\
(0.0156)\end{array}$ & & $\begin{array}{c}0.9668 \\
(0.0064)\end{array}$ & $\begin{array}{c}0.9644 \\
(0.0071)\end{array}$ & $\begin{array}{c}0.9476 \\
(0.0075)\end{array}$ & 0.923 \\
\hline
\end{tabular}

\begin{tabular}{|c|c|c|c|c|c|c|c|c|c|c|}
\hline \multicolumn{11}{|c|}{ Shock statistics } \\
\hline$\pi$ & - & $\begin{array}{c}1.0027 \\
(0.0001)\end{array}$ & $\begin{array}{c}1.0483 \\
(0.0018)\end{array}$ & - & $\begin{array}{c}1.0016 \\
(0.0001)\end{array}$ & $\begin{array}{c}1.0280 \\
(0.0010)\end{array}$ & - & $\begin{array}{c}1.0011 \\
(0.0001)\end{array}$ & $\begin{array}{c}1.0184 \\
(0.0006)\end{array}$ & - \\
\hline$\sigma_{\pi}$ & - & $\begin{array}{c}0.0531 \\
(0.0031)\end{array}$ & $\begin{array}{c}0.2960 \\
(0.0213)\end{array}$ & - & $\begin{array}{c}0.0525 \\
(0.0031)\end{array}$ & $\begin{array}{c}0.2439 \\
(0.0157)\end{array}$ & - & $\begin{array}{c}0.0523 \\
(0.0029)\end{array}$ & $\begin{array}{c}0.2271 \\
(0.0142)\end{array}$ & - \\
\hline$\sigma_{\Lambda}$ & - & $\begin{array}{c}0.0172 \\
(0.0010)\end{array}$ & $\begin{array}{c}0.0768 \\
(0.0047)\end{array}$ & - & 0 & 0 & - & $\begin{array}{c}0.0342 \\
(0.0019)\end{array}$ & $\begin{array}{c}0.1413 \\
(0.0090)\end{array}$ & - \\
\hline $\operatorname{corr}(\pi, z)$ & - & $\begin{array}{c}-0.1411 \\
(0.0731)\end{array}$ & $\begin{array}{l}-0.4943 \\
(0.0675)\end{array}$ & - & $\begin{array}{c}-0.0919 \\
(0.0684)\end{array}$ & $\begin{array}{l}-0.3399 \\
(0.0736)\end{array}$ & - & $\begin{array}{c}-0.0579 \\
(0.0757)\end{array}$ & $\begin{array}{c}-0.2390 \\
(0.0758)\end{array}$ & - \\
\hline $\operatorname{corr}(\Lambda, z)$ & - & $\begin{array}{c}-0.0714 \\
(0.0728)\end{array}$ & $\begin{array}{c}-0.2861 \\
(0.0748)\end{array}$ & - & $\begin{array}{c}0.0027 \\
(0.0672)\end{array}$ & $\begin{array}{c}0.0040 \\
(0.0634)\end{array}$ & - & $\begin{array}{c}0.0292 \\
(0.0757)\end{array}$ & $\begin{array}{c}0.1211 \\
(0.0750)\end{array}$ & - \\
\hline
\end{tabular}

Labor-market statistics

\begin{tabular}{|c|c|c|c|c|c|c|c|c|c|c|}
\hline$\sigma_{n} / \sigma_{y}$ & $\begin{array}{c}0.5798 \\
(0.0053)\end{array}$ & $\begin{array}{c}0.6049 \\
(0.0094)\end{array}$ & $\begin{array}{c}1.1238 \\
(0.0610)\end{array}$ & $\begin{array}{c}0.5088 \\
(0.0040)\end{array}$ & $\begin{array}{c}0.5255 \\
(0.0081)\end{array}$ & $\begin{array}{c}0.8325 \\
(0.0416)\end{array}$ & $\begin{array}{c}0.4363 \\
(0.0033)\end{array}$ & $\begin{array}{c}0.4625 \\
(0.0075)\end{array}$ & $\begin{array}{c}0.6666 \\
(0.0355)\end{array}$ & 0.729 \\
\hline$\sigma_{h} / \sigma_{y}$ & - & $\begin{array}{c}0.5795 \\
(0.0055)\end{array}$ & $\begin{array}{c}0.5936 \\
(0.0070)\end{array}$ & - & $\begin{array}{c}0.5067 \\
(0.0038)\end{array}$ & $\begin{array}{c}0.5149 \\
(0.0038)\end{array}$ & - & $\begin{array}{c}0.4499 \\
(0.0030)\end{array}$ & $\begin{array}{c}0.4436 \\
(0.0057)\end{array}$ & - \\
\hline$\sigma_{y / n} / \sigma_{y}$ & $\begin{array}{c}0.4496 \\
(0.0102)\end{array}$ & $\begin{array}{c}0.4432 \\
(0.0122)\end{array}$ & $\begin{array}{c}0.5559 \\
(0.0657)\end{array}$ & $\begin{array}{c}0.5092 \\
(0.0071)\end{array}$ & $\begin{array}{c}0.5074 \\
(0.0088)\end{array}$ & $\begin{array}{c}0.5293 \\
(0.0438)\end{array}$ & $\begin{array}{c}0.5733 \\
(0.0047)\end{array}$ & $\begin{array}{c}0.5591 \\
(0.0080)\end{array}$ & $\begin{array}{c}0.5939 \\
(0.0397)\end{array}$ & 0.576 \\
\hline $\operatorname{corr}(n, h)$ & - & $\begin{array}{c}0.9902 \\
(0.0023)\end{array}$ & $\begin{array}{c}0.9202 \\
(0.0157)\end{array}$ & - & $\begin{array}{c}0.9851 \\
(0.0034)\end{array}$ & $\begin{array}{c}0.8601 \\
(0.0287)\end{array}$ & - & $\begin{array}{c}0.9788 \\
(0.0050)\end{array}$ & $\begin{array}{c}0.7485 \\
(0.0551)\end{array}$ & - \\
\hline $\operatorname{corr}(n, y)$ & $\begin{array}{c}0.9779 \\
(0.0053)\end{array}$ & $\begin{array}{c}0.9666 \\
(0.0054)\end{array}$ & $\begin{array}{c}0.8696 \\
(0.0245)\end{array}$ & $\begin{array}{c}0.9822 \\
(0.0041)\end{array}$ & $\begin{array}{c}0.9692 \\
(0.0046)\end{array}$ & $\begin{array}{c}0.8490 \\
(0.0281)\end{array}$ & $\begin{array}{c}0.9875 \\
(0.0029)\end{array}$ & $\begin{array}{c}0.9743 \\
(0.0042)\end{array}$ & $\begin{array}{c}0.8194 \\
(0.0380)\end{array}$ & 0.830 \\
\hline $\operatorname{corr}(y / n, y)$ & $\begin{array}{c}0.9633 \\
(0.0069)\end{array}$ & $\begin{array}{c}0.9371 \\
(0.0077)\end{array}$ & $\begin{array}{c}0.0451 \\
(0.0894)\end{array}$ & $\begin{array}{c}0.9824 \\
(0.0034)\end{array}$ & $\begin{array}{c}0.9670 \\
(0.0046)\end{array}$ & $\begin{array}{c}0.5566 \\
(0.0655)\end{array}$ & $\begin{array}{c}0.9928 \\
(0.0015)\end{array}$ & $\begin{array}{c}0.9825 \\
(0.0027)\end{array}$ & $\begin{array}{c}0.7665 \\
(0.0438)\end{array}$ & 0.715 \\
\hline $\operatorname{corr}(n, y / n)$ & $\begin{array}{c}0.8858 \\
(0.0235)\end{array}$ & $\begin{array}{c}0.8165 \\
(0.0238)\end{array}$ & $\begin{array}{c}-0.4499 \\
(0.0876)\end{array}$ & $\begin{array}{c}0.9299 \\
(0.0148)\end{array}$ & $\begin{array}{c}0.8745 \\
(0.0175)\end{array}$ & $\begin{array}{c}0.0377 \\
(0.1090)\end{array}$ & $\begin{array}{c}0.9615 \\
(0.0085)\end{array}$ & $\begin{array}{c}0.9154 \\
(0.0131)\end{array}$ & $\begin{array}{c}0.2637 \\
(0.1164)\end{array}$ & 0.220 \\
\hline
\end{tabular}

Note: $\quad{ }^{a}$ The description of the U.S. data used is provided in Appendix B.

${ }^{b}$ In the case $\eta=1.0$, the top five statistics for $K \& P$ and $H A$ models are identical. 
Table 2. Selected statistics for the U.S. and artificial economies: the addilog case.

\begin{tabular}{|c|c|c|c|c|c|c|c|}
\hline \multirow{2}{*}{ Statistic } & \multicolumn{3}{|c|}{$\theta=0.5$} & \multicolumn{3}{|c|}{$\theta=2.0$} & \multirow{2}{*}{$\begin{array}{c}\text { U.S. } \\
\text { Economy }\end{array}$} \\
\hline & $K \& P$ & $\begin{array}{c}H A \\
v=0.2\end{array}$ & $\begin{array}{c}H A \\
v=0.4\end{array}$ & $K \& P$ & $\begin{array}{c}H A \\
v=0.2\end{array}$ & $\begin{array}{c}H A \\
v=0.4\end{array}$ & \\
\hline$\sigma_{y}$ & $\begin{array}{c}1.4684 \\
(0.1551)\end{array}$ & $\begin{array}{c}1.4837 \\
(0.1537)\end{array}$ & $\begin{array}{c}1.5066 \\
(0.1642)\end{array}$ & $\begin{array}{c}1.1823 \\
(0.1248)\end{array}$ & $\begin{array}{c}1.1751 \\
(0.1246)\end{array}$ & $\begin{array}{c}1.1917 \\
(0.1234)\end{array}$ & 1.755 \\
\hline$\sigma_{i} / \sigma_{y}$ & $\begin{array}{c}3.9768 \\
(0.0828)\end{array}$ & $\begin{array}{c}3.9108 \\
(0.0797)\end{array}$ & $\begin{array}{c}3.9727 \\
(0.0747)\end{array}$ & $\begin{array}{c}3.8230 \\
(0.0666)\end{array}$ & $\begin{array}{c}3.8297 \\
(0.0682)\end{array}$ & $\begin{array}{c}3.8190 \\
(0.0651)\end{array}$ & 2.731 \\
\hline$\sigma_{c} / \sigma_{y}$ & $\begin{array}{c}0.2894 \\
(0.0150)\end{array}$ & $\begin{array}{c}0.3013 \\
(0.0136)\end{array}$ & $\begin{array}{c}0.2955 \\
(0.0137)\end{array}$ & $\begin{array}{c}0.3251 \\
(0.0127)\end{array}$ & $\begin{array}{c}0.3162 \\
(0.0124)\end{array}$ & $\begin{array}{c}0.3181 \\
(0.0135)\end{array}$ & 0.476 \\
\hline $\operatorname{corr}(i, y)$ & $\begin{array}{c}0.9876 \\
(0.0033)\end{array}$ & $\begin{array}{c}0.9879 \\
(0.0031)\end{array}$ & $\begin{array}{c}0.9873 \\
(0.0035)\end{array}$ & $\begin{array}{c}0.9882 \\
(0.0028)\end{array}$ & $\begin{array}{c}0.9890 \\
(0.0027)\end{array}$ & $\begin{array}{c}0.9882 \\
(0.0028)\end{array}$ & 0.979 \\
\hline $\operatorname{corr}(c, y)$ & $\begin{array}{c}0.8785 \\
(0.0190)\end{array}$ & $\begin{array}{c}0.8950 \\
(0.0163)\end{array}$ & $\begin{array}{c}0.8832 \\
(0.0168)\end{array}$ & $\begin{array}{c}0.9106 \\
(0.0141)\end{array}$ & $\begin{array}{c}0.9104 \\
(0.0146)\end{array}$ & $\begin{array}{c}0.9036 \\
(0.0148)\end{array}$ & 0.923 \\
\hline \multicolumn{8}{|c|}{ Shock statistics } \\
\hline$\pi$ & - & $\begin{array}{c}1.0032 \\
(0.0001)\end{array}$ & $\begin{array}{c}1.0595 \\
(0.0022)\end{array}$ & - & $\begin{array}{c}1.0008 \\
(0.0001)\end{array}$ & $\begin{array}{c}1.0135 \\
(0.0005)\end{array}$ & - \\
\hline$\sigma_{\pi}$ & - & $\begin{array}{c}0.0535 \\
(0.0032)\end{array}$ & $\begin{array}{c}0.3335 \\
(0.0256)\end{array}$ & - & $\begin{array}{c}0.0522 \\
(0.0031)\end{array}$ & $\begin{array}{c}0.2192 \\
(0.0130)\end{array}$ & - \\
\hline$\sigma_{X}$ & - & $\begin{array}{c}0.0262 \\
(0.0015)\end{array}$ & $\begin{array}{c}0.1215 \\
(0.0076)\end{array}$ & - & $\begin{array}{c}0.0521 \\
(0.0031)\end{array}$ & $\begin{array}{c}0.2120 \\
(0.0125)\end{array}$ & - \\
\hline $\operatorname{corr}(\pi, z)$ & - & $\begin{array}{c}-0.1681 \\
(0.0733)\end{array}$ & $\begin{array}{c}-0.5476 \\
(0.0688)\end{array}$ & - & $\begin{array}{c}-0.0493 \\
(0.0693)\end{array}$ & $\begin{array}{c}-0.1794 \\
(0.0733)\end{array}$ & - \\
\hline $\operatorname{corr}(X, z)$ & - & $\begin{array}{l}-0.0837 \\
(0.0739)\end{array}$ & $\begin{array}{l}-0.3360 \\
(0.0785)\end{array}$ & - & $\begin{array}{c}0.0278 \\
(0.0697)\end{array}$ & $\begin{array}{c}0.0870 \\
(0.0739)\end{array}$ & - \\
\hline \multicolumn{8}{|c|}{ Labor-market statistics } \\
\hline$\sigma_{n} / \sigma_{y}$ & $\begin{array}{c}0.6197 \\
(0.0053)\end{array}$ & $\begin{array}{c}0.6375 \\
(0.0097)\end{array}$ & $\begin{array}{c}1.3072 \\
(0.0664)\end{array}$ & $\begin{array}{c}0.3778 \\
(0.0032)\end{array}$ & $\begin{array}{c}0.3876 \\
(0.0062)\end{array}$ & $\begin{array}{c}0.5329 \\
(0.0286)\end{array}$ & 0.729 \\
\hline$\sigma_{h} / \sigma_{y}$ & - & $\begin{array}{c}0.6089 \\
(0.0051)\end{array}$ & $\begin{array}{c}0.6479 \\
(0.0081)\end{array}$ & - & $\begin{array}{c}0.3785 \\
(0.0036)\end{array}$ & $\begin{array}{c}0.3917 \\
(0.0096)\end{array}$ & - \\
\hline$\sigma_{y / n} / \sigma_{y}$ & $\begin{array}{c}0.4069 \\
(0.0103)\end{array}$ & $\begin{array}{c}0.4079 \\
(0.0117)\end{array}$ & $\begin{array}{c}0.6282 \\
(0.0733)\end{array}$ & $\begin{array}{c}0.6330 \\
(0.0050)\end{array}$ & $\begin{array}{c}0.6329 \\
(0.0065)\end{array}$ & $\begin{array}{c}0.6571 \\
(0.0283)\end{array}$ & 0.576 \\
\hline $\operatorname{corr}(n, h)$ & - & $\begin{array}{c}0.9919 \\
(0.0019)\end{array}$ & $\begin{array}{c}0.9360 \\
(0.0136)\end{array}$ & - & $\begin{array}{c}0.9672 \\
(0.0076)\end{array}$ & $\begin{array}{c}0.6279 \\
(0.0710)\end{array}$ & - \\
\hline $\operatorname{corr}(n, y)$ & $\begin{array}{c}0.9830 \\
(0.0044)\end{array}$ & $\begin{array}{c}0.9725 \\
(0.0044)\end{array}$ & $\begin{array}{c}0.8851 \\
(0.0224)\end{array}$ & $\begin{array}{c}0.9820 \\
(0.0042)\end{array}$ & $\begin{array}{c}0.9670 \\
(0.0049)\end{array}$ & $\begin{array}{c}0.8003 \\
(0.0375)\end{array}$ & 0.830 \\
\hline $\operatorname{corr}(y / n, y)$ & $\begin{array}{c}0.9605 \\
(0.0079)\end{array}$ & $\begin{array}{c}0.9317 \\
(0.0089)\end{array}$ & $\begin{array}{c}-0.2482 \\
(0.0824)\end{array}$ & $\begin{array}{c}0.9937 \\
(0.0013)\end{array}$ & $\begin{array}{c}0.9878 \\
(0.0018)\end{array}$ & $\begin{array}{c}0.8737 \\
(0.0248)\end{array}$ & 0.715 \\
\hline $\operatorname{corr}(n, y / n)$ & $\begin{array}{c}0.8931 \\
(0.0232)\end{array}$ & $\begin{array}{c}0.8217 \\
(0.0238)\end{array}$ & $\begin{array}{c}-0.6678 \\
(0.0554)\end{array}$ & $\begin{array}{c}0.9546 \\
(0.0101)\end{array}$ & $\begin{array}{c}0.9154 \\
(0.0122)\end{array}$ & $\begin{array}{c}0.4098 \\
(0.0938)\end{array}$ & 0.220 \\
\hline
\end{tabular}

Note: ${ }^{a}$ The description of the U.S. data used is provided in Appendix B. 
We now turn to the predictions of the heterogeneous-agent $(H A)$ variant of the model. We shall first recall that the effect of idiosyncratic productivity shocks on the aggregate dynamics is fully summarized by the shocks $\Lambda_{t}$ and $\pi_{t}$ in the CRRA case and $X_{t}$ and $\pi_{t}$ in the addilog case. The preference shocks, $\Lambda_{t}$ and $X_{t}$, affect all of the model's variables, whereas the labor-input shock, $\pi_{t}$, influences only physical hours worked, $n_{t}$. (Note that in the "log-log" case, there is no preference shock but still there is a labor-input shock). Given that the technology shock, $\theta_{t}$, follows the same stochastic process in the homogeneous- and heterogeneous-agent economies, any difference between aggregate fluctuations of the two economies must come from the preference and labor-input shocks.

The regularities we observe in Tables 1 and 2 are as follows: In all the considered cases, the predictions of the heterogeneous- and homogeneous-agent models about the cyclical behavior of output, investment and consumption are practically identical. We therefore conclude that the effect of the preference shocks on aggregate dynamics is not quantitatively significant. This result is a consequence of the very low volatility of the preference shocks (see $\sigma_{\Lambda}$ and $\sigma_{X}$ in the CRRA and addilog cases, respectively).

In contrast, the labor-market statistics, produced by the heterogeneousand homogeneous-agent versions of the model, can differ markedly. The heterogeneous-agent model, for example, can generate the correlation between working hours and productivity, which ranges from strongly positive to strongly negative. A negative correlation is obtained when the values of $\eta$ and $\sigma$ in the CRRA and addilog cases, respectively, are lower than one and when the volatility of idiosyncratic shocks is large $(\nu=0.4)$. A similar tendency is observed regarding the correlation between productivity and output.

What, precisely, reduces the above correlations in the heterogeneousagent case as compared to the homogeneous-agent one? Given that the preference shocks have little impact on aggregate dynamics, the behavior of efficiency hours worked in the heterogeneous-agent model, $h_{t}$, is roughly the same as that of physical hours worked in the homogeneous-agent model. In turn, the dynamics of physical hours worked in the heterogeneous-agent model, $n_{t}$, can be characterized by $h_{t}$ and $\pi_{t}$. In particular, according to (14), we have

$$
d n_{t}=-\left(1-h_{t}\right) d \pi_{t}+\pi_{t} d h_{t}
$$

where $d x_{t}$ denotes a differential of a variable $x_{t}$. Suppose that the economy 
experiences a change in technology, $d \theta_{t}$. As follows from Tables 1 and 2 , the correlation between the technology shock $\theta_{t}$ and the labor-input shock $\pi_{t}$ is negative, which indicates that the sign of $d \pi_{t}$ is opposite to that of the technology change, $d \theta_{t}$. Furthermore, in all the cases considered, we have $\pi_{t}>1 .^{5}$ These two results imply that physical hours worked are more responsive to technological changes than efficiency hours worked, $d n_{t}>d h_{t}{ }^{6}{ }^{6}$ Under some parametrizations, the effect associated with idiosyncratic uncertainty is so strong that the volatility of working hours in the heterogeneous-agent model exceeds the volatility of output, $\sigma_{n} / \sigma_{y}>1$. The consequence is that a positive (negative) technology shock drives the productivity $y_{t} / n_{t}$ down (up), which makes the correlation between $n_{t}$ and $y_{t} / n_{t}$ negative. The problem we face, in this case, is exactly the opposite to the one we had in the benchmark homogeneous-agent setup!

We also perform the sensitivity analysis. First, we explore the robustness of our results to variations in the utility function parameters, such as $\eta$ in the CRRA case and $\gamma, \sigma$ in the addilog case. The tendencies described in this section proved to be robust to such modifications. Furthermore, we consider an alternative specification of the process for idiosyncratic shocks, the one that allows for both temporary and permanent differences in skills across agents, $\beta_{t}^{s}=\beta^{s}\left(e_{t}^{s}+\beta_{t}\right)$, where $\beta^{s}$ is the long-run average of skills of the agent $s$. To calibrate this version of the model, we assume the same processes for $e_{t}^{s}$ and $\beta_{t}$ as before, and we proxy $\beta^{s}$ by the variable "hourly earnings of the household head" (the PSID mnemonics 17536). By setting $b_{t}^{s}=\beta^{s} / \int_{S} \beta^{s} d \omega^{s}$, we solve for the welfare weights satisfying (37) and (43) in the CRRA and addilog cases, respectively. We find that the predictions produced by this version of the model are very similar to those we described before.

\footnotetext{
${ }^{5}$ Note that even if $\pi_{t}$ exhibits no fluctuations, i.e., $\pi_{t}=\pi$ for all $t$, it can still affect aggregate dynamics because the value of $\pi$ determines the volatility of physical hours worked. In a neoclassical growth model with permanent differences in skills considered in Maliar and Maliar (2001), the presence of such a constant parameter improves the predictions of the model on labor-market statistics.

${ }^{6}$ Thus, our heterogeneous-agent model reproduces the empirical regularity, documented by Hansen (1993) and Kydland and Prescott (1993), that physical hours worked are more volatile than efficiency hours worked.
} 


\section{Conclusion}

This paper studies the implications of the neoclassical growth model, where agents experience idiosyncratic shocks to earnings. We show that if markets are complete, and if agents have identical preferences of either the CRRA or the addilog type, then there exists a closed-form expression for the social utility function. By using this result, we construct a representative-consumer model that describes the aggregate dynamics of the heterogeneous-agent economy. Under our construction, the effect of idiosyncratic uncertainty on the aggregate dynamics is summarized by three kinds of shocks: to technology, to preferences and to labor input. In a calibrated version of the model, we find that the effect of the preference shocks on the economy's aggregate behavior is modest. The labor-input shocks, on the contrary, play an important role in the aggregate dynamics. For example, unlike the benchmark Kydland and Prescott's (1982) setup, our heterogeneous-agent model can generate either procyclical, acyclical or countercyclical behavior of labor productivity, depending on the model's parameterization.

We should point out that the possibility of aggregation, in the context of the neoclassical growth model, is not limited to the two settings considered in this paper. Several possible extensions of our results are as follows: First, our example of aggregation under the assumption of the addilog utility functions can be generalized to the case in which agents have any identical additive utility functions, with each additive component being a member of the Hyperbolic Absolute Risk Aversion (HARA) class. Secondly, our aggregation results also hold when the individual utility functions are modified to include agent-specific subsistence levels of consumption and leisure. Thirdly, in all the cases distinguished, we can achieve the same kind of aggregation if agents face two types of idiosyncratic shocks, one to skills and another to preferences, with the latter shock being introduced as in Example $1 .^{7}$ In particular, for the two-shock settings with the CRRA and addilog utility functions, the results of our Propositions 2, 3 and 4 carry over with a formal replacement of $\lambda^{s}$ by the term $\lambda^{s} \phi_{t}^{s}$. Finally, if the individual utility functions are given by an increasing power transformation of the Constant Elasticity of Substitution (CES) functions and are identical up to possibly different subsistence levels, then the aggregation is possible in the economy

\footnotetext{
${ }^{7}$ The fact that the economy with idiosyncratic shocks to the discount factor allows for aggregation was pointed out to us by associate editor Per Krusell.
} 
with preference shocks (but not in the one with the productivity shocks).

As a final comment, we shall mention that the technology and preference shocks in the constructed representative-consumer models can be viewed as aggregate supply and demand shocks, respectively. Supply shocks are commonly used in current macroeconomic literature. Demand shocks have been believed, for a long time, to play an important role in economics, e.g., in Keynesian economies, but they are rarely used nowadays. Our aggregation results provide theoretical foundations for the assumption of aggregate demand shocks. For the moment, we have not found sufficient empirical evidence to support such shocks. This issue warrants further investigation. 


\section{Appendices}

Appendix A presents the proofs to Propositions 1-4. Appendix B describes the data used for computing the statistics on the U.S. economy.

\subsection{Appendix A}

Proof of Proposition 1. We prove this proposition by showing that a competitive equilibrium in the decentralized economy (1) - (4) satisfies the optimality conditions of the planner's problem (5), (6).

The First Order Conditions (FOCs) of the consumer's optimization problem (1), (2) with respect to $m_{t+1}^{s}(B), k_{t+1}^{s}, c_{t}^{s}$ and $n_{t}^{s}$, and the transversality condition, respectively, are

$$
\begin{gathered}
\lambda_{t}^{s} p_{t}(B)=\delta \lambda_{t+1}^{s}\left(B^{\prime}\right) \cdot \Pi\left\{B_{t+1}=B^{\prime} \mid B_{t}=B\right\}_{B^{\prime}, B \in \Re}, \\
\lambda_{t}^{s}=\delta E_{t}\left[\lambda_{t+1}^{s}\left(1-d+\theta_{t+1} \alpha k_{t+1}^{\alpha-1}\left(g^{t+1} h_{t+1}\right)^{1-\alpha}\right)\right] \\
u_{1}\left(c_{t}^{s}, 1-n_{t}^{s}, g^{t}\right)=\lambda_{t}^{s} \\
u_{2}\left(c_{t}^{s}, 1-n_{t}^{s}, g^{t}\right)=\lambda_{t}^{s} \theta_{t}(1-\alpha) k_{t}^{\alpha}\left(g^{t} h_{t}\right)^{-\alpha} g^{t} b_{t}^{s} \\
\lim _{t \rightarrow \infty} E_{0}\left[\delta^{t} \lambda_{t}^{s}\left(k_{t+1}^{s}+\int_{\Re} p_{t}(B) m_{t+1}^{s}(B) d B\right)\right]=0
\end{gathered}
$$

where $\lambda_{t}^{s}$ is the Lagrange multiplier associated with the agent's budget constraint (2), and $u_{1}$ and $u_{2}$ denote the first-order partial derivatives of the function $u$ with respect to the first and second arguments, respectively. To obtain conditions (18) and (20), we use the fact that, in equilibrium, $r_{t}$ and $w_{t}$ are equal to the marginal products of capital and labor, respectively.

By FOC (17), for any two agents $s, s^{\prime} \in S$, we obtain

$$
\frac{\lambda_{t}^{s}}{\lambda_{t}^{s^{\prime}}}=\frac{\lambda_{t+1}^{s}}{\lambda_{t+1}^{s^{\prime}}}=\ldots=\frac{\lambda^{s \prime}}{\lambda^{s}} \quad \text { for all } t .
$$

Thus, we have that the ratio of marginal utilities of any two consumers is constant across time and states of nature, which is the usual consequence 
of the assumption of complete markets. Result (22) implies that the individual Lagrange multipliers can be represented in the form $\lambda_{t}^{s}=\lambda_{t} / \lambda^{s}$ with $\int_{S} \lambda^{s} d \omega^{s}=1$, which allows us to re-write conditions (18) - (21) as follows:

$$
\begin{gathered}
\lambda_{t}=\delta E_{t}\left[\lambda_{t+1}\left(1-d+\theta_{t+1} \alpha k_{t+1}^{\alpha-1}\left(g^{t+1} h_{t+1}\right)^{1-\alpha}\right)\right], \\
\lambda^{s} u_{1}\left(c_{t}^{s}, 1-n_{t}^{s}, g^{t}\right)=\lambda_{t}, \\
\lambda^{s} u_{2}\left(c_{t}^{s}, 1-n_{t}^{s}, g^{t}\right)=\lambda_{t} \theta_{t}(1-\alpha) k_{t}^{\alpha}\left(g^{t} h_{t}\right)^{-\alpha} g^{t} b_{t}^{s}, \\
\lim _{t \rightarrow \infty} E_{0}\left[\delta^{t} \lambda_{t}\left(k_{t+1}^{s}+\int_{\Re} p_{t}(B) m_{t+1}^{s}(B) d B\right)\right]=0 .
\end{gathered}
$$

Note also that if transversality condition (26) of each agent $s$ is satisfied, then we have

$$
\lim _{t \rightarrow \infty} E_{0}\left[\delta^{t} \lambda_{t} k_{t+1}\right]=0
$$

This follows after integrating (26) over the set of agents and imposing market clearing conditions for claims, $\int_{S} m_{t+1}^{s}(B) d \omega^{s}=0$ for all $B \in \Re$.

Consider now the planner's problem (5), (6). The FOCs of the subproblem (5) with respect to $c_{t}^{s}$ and $n_{t}^{s}$, correspondingly, are

$$
\begin{gathered}
\lambda^{s} u_{1}\left(c_{t}^{s}, 1-n_{t}^{s}, g^{t}\right)=\varphi_{t}, \\
\lambda^{s} u_{2}\left(c_{t}^{s}, 1-n_{t}^{s}, g^{t}\right)=\varkappa_{t} b_{t}^{s},
\end{gathered}
$$

where $\varphi_{t}$ and $\varkappa_{t}$ are the Lagrange multipliers associated with the constraints on the aggregate consumption and labor, respectively. The envelope conditions of the subproblem (5) are

$$
\begin{aligned}
& U_{1}\left(c_{t}, 1-h_{t}, g^{t},\left\{\lambda^{s}, b_{t}^{s}\right\}^{s \in S}\right)=\varphi_{t}, \\
& U_{2}\left(c_{t}, 1-h_{t}, g^{t},\left\{\lambda^{s}, b_{t}^{s}\right\}^{s \in S}\right)=\varkappa_{t},
\end{aligned}
$$


where $U_{1}$ and $U_{2}$ denote the first-order partial derivatives of the function $U$ with respect to the first and second arguments, respectively.

By finding the FOCs of the subproblem (6) and its transversality condition and by combining them with $(28)-(31)$, we obtain that the solution to the planner's problem is described by conditions $(23)-(25)$ and $(27)$, which proves the statement of the proposition.

Proof of Proposition 2. Under the assumption of the CRRA utility function, FOCs (28) and (29), respectively, are

$$
\begin{gathered}
\lambda^{s} \mu\left(c_{t}^{s}\right)^{\mu(1-\eta)-1}\left(1-n_{t}^{s}\right)^{(1-\mu)(1-\eta)}\left(g^{t}\right)^{(1-\mu)(1-\eta)}=\varphi_{t}, \\
\lambda^{s}(1-\mu)\left(c_{t}^{s}\right)^{\mu(1-\eta)}\left(1-n_{t}^{s}\right)^{(1-\mu)(1-\eta)-1}\left(g^{t}\right)^{(1-\mu)(1-\eta)}=\varkappa_{t} b_{t}^{s} .
\end{gathered}
$$

By solving (32), (33) with respect to $c_{t}^{s}$ and $\left(1-n_{t}^{s}\right) b_{t}^{s}$, we obtain

$$
\begin{gathered}
c_{t}^{s}=\left(\frac{\mu}{\varphi_{t}}\right)^{1 / \eta}\left(\frac{\varphi_{t}(1-\mu)}{\varkappa_{t} \mu g^{t}}\right)^{(1-\mu)(1-\eta) / \eta} \cdot\left(\lambda^{s}\right)^{1 / \eta}\left(b_{t}^{s}\right)^{-(1-\mu)(1-\eta) / \eta} \\
\left(1-n_{t}^{s}\right) b_{t}^{s}=\left(\frac{\mu}{\varphi_{t}}\right)^{1 / \eta}\left(\frac{\varphi_{t}(1-\mu)}{\varkappa_{t} \mu g^{t}}\right)^{(1-\mu(1-\eta)) / \eta} \cdot\left(\lambda^{s}\right)^{1 / \eta}\left(b_{t}^{s}\right)^{-(1-\mu)(1-\eta) / \eta} .
\end{gathered}
$$

Integration of (34) and (35) yields $c_{t}$ and $\left(1-h_{t}\right)$, respectively. We then divide $c_{t}^{s}$ by $c_{t}$ and $\left(1-n_{t}^{s}\right) b_{t}^{s}$ by $\left(1-h_{t}\right)$ and re-arrange the terms to get

$$
\begin{gathered}
c_{t}^{s}=\frac{\left(\lambda^{s}\right)^{1 / \eta}\left(b_{t}^{s}\right)^{-(1-\mu)(1-\eta) / \eta}}{\int_{S}\left(\lambda^{s}\right)^{1 / \eta}\left(b_{t}^{s}\right)^{-(1-\mu)(1-\eta) / \eta} d \omega^{s}} \cdot c_{t}, \\
\left(1-n_{t}^{s}\right)=\frac{\left(\lambda^{s}\right)^{1 / \eta}\left(b_{t}^{s}\right)^{(\mu(1-\eta)-1) / \eta}}{\int_{S}\left(\lambda^{s}\right)^{1 / \eta}\left(b_{t}^{s}\right)^{-(1-\mu)(1-\eta) / \eta} d \omega^{s}} \cdot\left(1-h_{t}\right) .
\end{gathered}
$$

The result of the proposition follows after substitution of (36) and (37) into the definition of the social utility function (5). $\|$ 
Proof of Proposition 3. In the case of the addilog utility function, FOCs (28) and (29), respectively, take the form

$$
\begin{gathered}
\lambda^{s}\left(c_{t}^{s}\right)^{-\gamma}=\varphi_{t}, \\
\lambda^{s} A g^{t(1-\gamma)}\left(1-n_{t}^{s}\right)^{-\sigma}=\varkappa_{t} b_{t}^{s} .
\end{gathered}
$$

Solving (38), (39) for $c_{t}^{s}$ and $\left(1-n_{t}^{s}\right) b_{t}^{s}$ yields

$$
\begin{gathered}
c_{t}^{s}=\varphi_{t}^{-1 / \gamma} \cdot\left(\lambda^{s}\right)^{1 / \gamma}, \\
\left(1-n_{t}^{s}\right) b_{t}^{s}=\left(A g^{t(1-\gamma)} / \varkappa_{t}\right)^{1 / \sigma} \cdot\left(\lambda^{s}\right)^{1 / \sigma}\left(b_{t}^{s}\right)^{1-1 / \sigma} .
\end{gathered}
$$

We compute $c_{t}$ and $\left(1-h_{t}\right)$ by integrating (40) and (41), respectively. After dividing $c_{t}^{s}$ by $c_{t}$ and $\left(1-n_{t}^{s}\right) b_{t}^{s}$ by $\left(1-h_{t}\right)$ and re-arranging the terms, we obtain

$$
\begin{gathered}
c_{t}^{s}=\frac{\left(\lambda^{s}\right)^{1 / \gamma}}{\int_{S}\left(\lambda^{s}\right)^{1 / \gamma} d \omega^{s}} \cdot c_{t}, \\
\left(1-n_{t}^{s}\right)=\frac{\left(\lambda^{s}\right)^{1 / \sigma}\left(b_{t}^{s}\right)^{-1 / \sigma}}{\int_{S}\left(\lambda^{s}\right)^{1 / \sigma}\left(b_{t}^{s}\right)^{1-1 / \sigma} d \omega^{s}} \cdot\left(1-h_{t}\right) .
\end{gathered}
$$

Substitution of (42) and (43) into definition (5) completes the proof.

Proof of Proposition 4. In the CRRA case, conditions (14) and (15) follow after integration of (37). Similarly, in the addilog case, conditions (14) and (16) follow after integration of (43).

\subsection{Appendix B}

To compute the empirical statistics, we use quarterly data on the U.S. economy ranging from $1959: 3$ to $1998: 3$. The variable consumption $c_{t}$ in the model is defined as real personal expenditures on nondurables and services in the data. Investment $i_{t}$ in the model is real personal consumption 
of durables and real fixed private investment in the data. Consequently, the series for output are constructed by adding-up consumption and investment, $y_{t}=c_{t}+i_{t}$. The variable working hours $n_{t}$ in the model is defined as the level of the civilian employment premultiplied by average weakly hours worked in private nonagricultural establishments in the data. Before computing the estimates, the constructed series are converted in per-capita terms by using the efficiency measure of the U.S. population. The data are taken from the Federal Reserve Bank of Saint-Louis data base (mnemonics FPIC92, PCEDG92, PCENDC92, PCECS92, CE16OV, AWHNONAG). The sources for these series are the U.S. Department of Labor and the U.S. Department of Commerce.

As a measure of labor productivity (wage), we use the variable $y_{t} / n_{t}$. To verify that the constructed measure of labor productivity behaves similarly to the one in the U.S. economy, we compared this measure to the CITIBASE variable $L B O U T U$, which is the output per-hour of all the persons in the nonagricultural business sector. We find that the two measures are very similar. Specifically, if instead of $y_{t} / n_{t}$, we use the variable $L B O U T U$, then we have $\sigma_{y / n} / \sigma_{y}=0.583, \operatorname{corr}(y / n, n)=0.220$ and $\operatorname{corr}(y / n, y)=0.543$, which are close to the corresponding statistics reported in the tables. 


\section{References}

[1] Aiyagari, R. (1994), "Uninsured idiosyncratic risk and aggregate saving," Quarterly Journal of Economics, 109, 659-684.

[2] Atkeson, A. and Ogaki, M. (1996), "Wealth-varying intertemporal elasticities of substitution: evidence from panel and aggregate data," Journal of Monetary Economics, 38, 507-535.

[3] Caselli, F. and Ventura, J. (2000), "A representative consumer theory of distribution," American Economic Review, 90, 909-926.

[4] Castañeda, A., Diaz-Giménez, J. and Ríos-Rull, J.V. (1998), "Exploring the income distribution business cycle dynamics," Journal of Monetary Economics, 42, 93-130.

[5] Chatterjee, S. (1994), "Transitional dynamics and the distribution of wealth in a neoclassical growth model," Journal of Public Economics, $54,97-119$.

[6] Christiano, L. and Eichenbaum, M. (1992), "Current real-business-cycle theories and aggregate labor-market fluctuations," American Economic Review, 82, 430-450.

[7] Constantinides, G. (1982), "Intertemporal asset pricing with heterogeneous consumers and without demand aggregation," Journal of Business, 55, 253-267.

[8] den Haan, W. and Marcet, A. (1990), "Solving the stochastic growth model by parametrizing expectations," Journal of Business and Economic Statistics, 8, 31-34.

[9] Dunlop J. (1938), "The movements of real and money wage rates," Economic Journal, 48, 413-434.

[10] Gorman, W. (1953), "Community preference field," Econometrica, 21, 63.80 .

[11] Hansen, G. (1985), "Indivisible labor and the business cycle," Journal of Monetary Economics, 16, 309-328. 
[12] Hansen, G. (1993), "The cyclical and secular behavior of the labor input: comparing efficiency units and hours worked," Journal of Applied Econometrics, 8, 71-80.

[13] Huggett, M. (1993), "The risk free rate in heterogeneous-agent, incomplete-insurance economies," Journal of Economic Dynamics and Control, 17, 953-969.

[14] Juster, F. and Stafford, F. (1991), "The allocation of time: empirical findings, behavioral models, and problems of measurement," Journal of Economic Literature, 29, 471-522.

[15] Krusell, P. and Smith, A. (1998), "Income and wealth heterogeneity in the macroeconomy," Journal of Political Economy, 106, 867-896.

[16] Kydland, F. (1995), "Aggregate labor market fluctuations," in: T. Cooley, eds., Frontiers of Business Cycle Research, Princeton, NJ: Princeton University Press.

[17] Kydland, F. and Prescott, E. (1982), "Time to build and aggregate fluctuations," Econometrica, 50, 1345-1370.

[18] Kydland, F. and Prescott, E. (1993), "Cyclical movements of the labor input and its implicit real wage," Federal Reserve Bank of Cleveland Economic Review, 29, 12-23.

[19] Maliar, L. and Maliar, S. (2000), "Differential responses of labor supply across productivity groups," Journal of Macroeconomics, 22, 85-108.

[20] Maliar, L. and Maliar, S. (2001), "Heterogeneity in capital and skills in a neoclassical stochastic growth model," Journal of Economic Dynamics and Control, 25, 1367-1397.

[21] Mas-Colell, A., Whinston, M. and Green, J. (1995), Microeconomic Theory, Oxford: Oxford University Press.

[22] Negishi, T. (1960), "Welfare economics and the existence of an equilibrium for a competitive economy," Metroeconomica, 12, 92-97.

[23] Samuelson, P. (1956), "Social indifference curves," Quarterly Journal of Economics, 70, 1-22. 
[24] Shafer, W. (1977), "Revealed preferences and aggregation," Econometrica, 45, 1173-1182.

[25] Tarshis, L. (1939), "Changes in real and money wages," Economic Journal, 49, 150-154. 